\title{
'The Improvement of Educational Standarts of Academicians by Using Various Tools Offered by The Behavioural Change Matrix'
}

\author{
Necip Ozgur Iyilikci \\ Phd.Student Ege University, İzmir \\ Lecturer, Pamukkale University
}

Doi: 10.19044/esj.2017.c1p19 URL:http://dx.doi.org/10.19044/esj.2017.c1p19

\begin{abstract}
Within the bounds of behavioural economics, this paper offers some commitment tools for academicians by changing their behaviours in some specific issues to explore better way of improving educational quality. Increasing classroom participation, failure to assess students' exam papers fairly because of the false impression of the first answer, preferring complicated and confusing teahing methods due to reasons originating from heuristic knowledge; and lack of attention and available advisory bodies to students in nonclass time are considered among these. Depending on willingness and awaresness of lecturer, behavioural change matrix offers some commitment tools that can change their behaviours for attaining higher overall academic performance.
\end{abstract}

Keywords: Behavioural Change Matrix, Behavioural Economics, Teacher's Performance

\section{Introduction}

People are born free. They are born not only with certain responsibilities and obligation but with certain rights. According to the liberal view; people can make their own decisions and recognize their interests. So any external intervention may deteriorate their position and subsequently leads the whole society worse off. On the other hand,, paternalism does not focus on personel freedom at most times but rather it views people as the working elements of the whole society from which they acquire their identity and recognition proving an organic relation in the society. The reflection of a different approach to human nature becomes visible in social relations even in the shop floor. Like countries follow different paths and sometimes use blend of them people can find a middle path in which they make fundamental 
decisions about themselves and the world around them by receiving external support. The middle path is referred as 'Liberterian Paternalism'. People are not as rational as the assumption of the mainstream economic theory. They might hold irrational view to some extent. They might even be better utility maximizers under this condition. .

\section{Heuristics and two systems in brain}

Kahneman and Amos introduced two different systems in (system1 and system 2) brain which cause individuals to make different decisions. While the former requires fast and less effortfull thinking; the latter is slow and effortfull thinking process that provides a solid ground for high computational analysis.

Some neuro-scientists (Abed) suggest that brain operations functions through certain mechanism. That brain functions subject to certain mechanism. Brain tends to follow the way requiring the least effort that is, it usually chooses the solution that comes to mind first which is not necessarily be the right one. People could make rational or irrational decisions at the end of their thinking process; and do not usually act on behalf of their real interests.

Heuristics decision making takes part almost all dimensions of our daily life. For example, personal saving behavior of an individual would differ with respect to various phases along their life and this highlights changing personal attitudes of Heuristic Decision making. People may overweight their short-term interests heavily. Accordingly, a certain mechanism for overcoming psocrastination heuristic could be adopted to increase total saving.

People usually display proscraistinateeive behavior, however, in some situations requiring specific policies some undesired outcomes will be avoided.When an undone job is delayed to the future; it is usually because of short sightedness and myopic behavior of people. This is closely related with other heuristics like overconfidence and planning fallacy in which people usually overestimate their skills in certain tasks even if they are short of time for completing the task.

This commitment tool seems to work well in changing saving behavior in the US since it succeeded to reach numerous people. Further improvements on teacher's performance could be expected from behavioural tools and commitment tools naturally in this respect. This is what the present paper is all about, which aims academicians to be better equipped with certain commitment and behavioural tools.

In an empirical study conducted on three different classrooms, an academician requested three term papers with different set for different classrooms to be completed along the semester. Subject to the change on duration of the semester, the date of last course was postponed and accordingly students gained an impression that they have still enough time to complete all 
papers whereas the deadline was the last day of the semester for the first classroom, students choose determined three different days for submission. In the last class, the academician determined a three distinct compulsory submission days for three-student assignments. As a result of the study, the average grades was higher in the third classroom in which lecturers set compulsory submşssion dates for students. Collecting of term papers was completely under the influence paternalistic rules set by the academician. The lowest average score was determined with the first classroom in which students were free to choose their deadlines for three papers until yhe last day of the semester. Two practices of paper deadline yieled different results. In the third classroom, students determined three different deadlines. Indeed, the average score of the classroom under the libertarian paternalism was very close to the score of the one in which students were given mandatory submission dates. ('Predictably Irrational, The Hidden Forces that Shape Our dacisions', Dan Ariely, chapter 7, p. 145).

In this paper, some hurdles with educational issues in institutions given in the empirical case conducted in the respective course such as prepearing exam questions, assessing student's exam papers fairly, sparing nonclassroom time efficiently for students are addressed and it was aimed to introduce some convenient behavioural tools for academicians. Awareness and willingness are substantially important concepts in this respect as introduced by the Behavioural Change Matrix which offers variety of measures and behavioural tools for different combinations of willingness and awareness whether they are taken together or not.

Some remindings can be useful to change teacher's behavior by placing it in one of the quadrants of the behavioral change matrix.Taking both academician's awareness and willingness into account it allows utilization from the measures most likely effective in achieving this behavioural change such as communication, education, attention shifting, positive and negative incentives.

\section{Behavioural Change Matrix}

Behavioural change matrix is comprised of four quadrants. In the first one, individuals are aware of the problem and they are willing to act responsibly as well. The main measure to address issues in this quadrant is 'Attention Shifting' that aims to direct their attention onto a certain issues.

When personal willingness is high but this is accompanied with low awareness for certain issues, the second quadrant is used.The main measure to address this issue is to educate and communicate so that problems could be solved on the best possible way by raising individual!s awareness.

When personal awareness is high but this is accompanied with low willingness for these aforesaid issues, the third quadrant is used. In this group 
of individuals, there is high awareness level but they are willing to change their behavior. Punishments and rewards are considered as measures to address these issues.

If personel awareness and willingness levels are both low, the fourth quadrant offers some solutions. The main measure addressed for solutions is to offering incentives. Whereas

This paper addresses four problems that could be experienced by academicians. Whereas the two of them are about increasing efficiency and job satisfaction, the other two are related with classroom administration.

Since courses require certain percentage of attendance by course hours, students's attendance is usually based on only their obligation. As most of Academicians are aware of this fact, they might show poor interests to such students who are not eager to learn. Yet, it is still possible to attract their attention and to include them into the classroom environment by assigning them certain exercises and performing joint works. Some improvements are exactly possible thanks to teaching skills peculiar to every academician's store of knowledge. Academicians usually aware of this issue and usually show willingness to change it. This issue might consider the first quadrant in which awareness and willingness are highly important and accordingly 'shift of attention' is the prpminent issue Attention shifting aims to change the behavior in the desired direction often subliminally and to influence willingness.

The second quadrant of behavioural change matrix includes behavioural tools for avoiding the risk of false assessment in cases where academicians begin assessment process with the first question followed by others in sequence. When the first comment of student on the first question is quite satisfactory, it is probable that it has positive effect on assessment of the following questions. In evaluation of exam paper of students, reading the first question of all exam papers first and then use the same method to other questions in sequence can be a rule of thumb in this respect.

The problem could be sorted in the second quadrant of the behavioural change matrix because while willingness level is high, the awareness level is considered at low level. Once this potential fault is realized, they are willing to change their behavior to lessen this risk as long as this situation does really exist. .

The issue that advisor academicians sometimes do not spare adequate non-classroom time for students and this could be an issue, the students in the third quadrant may ask questions about the lecture or they need their guidance especially regarding their future professional life. Their academic advisors could better use of time and assists them better if they are better informed about student histories.

Course-related knowledge is considered heuristic since the subjects are newly introduced and not fully comprehended by students, especially by 
freshmen. Because academician's interest of field and their course subject usually do not contain cognitive convenience. Academician's laborious efforts may not bring success to students easily. For instance, an indifference curve is an analytical tool utilized by the consumer theory and its graphical illustrations may not make any sense for most of the freshmen. The teaching experience of well-known academicians could be valuable and beneficient in this respect.

\section{Conclusion}

Even the high quality they have, Academicians might still experience some problems. Altough these remindings might bring minor improvements through small changes, academician's classroom performance could reach their best to the adoption of these specific behavioural tools.

Willingness

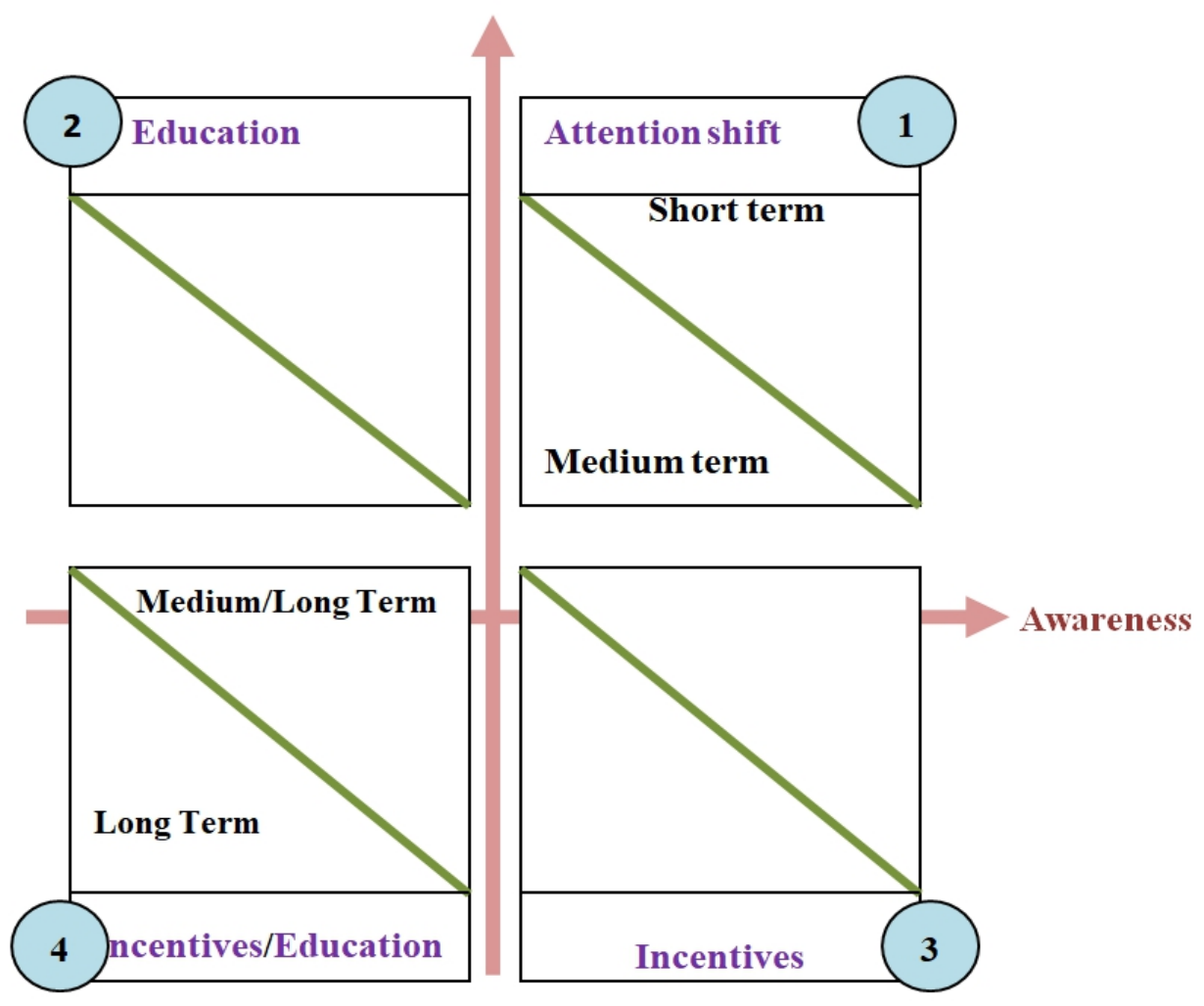

Figure 1: Behavioural Change Matrix 


\section{References:}

1. The Behavioural Economics Guide 2014, Edited by Alain Samson, with a foreword by George Loewenstein and Rory Sutherland.First Edition.

2. Ariely Dan, 'Predictably Irrational, The Hidden Forces that Shape Our Decisions.'

3. Kahneman Daniel, 'Thinking Fast and Slow' Penguin Books, 2012

4. Gerhard Fehr, Alain Karmn, Moritz Jager, Fehr Advice\&Partnners AG'The Behavioural Change Matrix-ATool for Evidence based Policy Making'

5. 'Behavioral Change Matrix'by Fehr Advice

6. Moore Robert, Education and the Ideology of Production, British Journal of Sociology of Education vol 8, no 2

7. Kumar Krisna, Understanding the Education System::An EcoBehavioural Approach,Economic and Political weekly,vol 44,no 23

8. Gazici H. Haim, Coping with Occupat,onal stress among teachers: A cross-cultural study comperative education vol 29 , no 1 